\title{
Serer Language
}

National Cancer Institute

\section{Source}

National Cancer Institute. Serer Language. NCI Thesaurus. Code C154132.

A Niger-Congo language spoken by the Serer people of Senegal and Gambia. 